\title{
13 A HERMENEUTIC INTERPRETATION OF THE EFFECT OF COMPUTERIZED BPR TOOLS ON REDESIGN EFFECTIVENESS IN TWO ORGANIZATIONS ${ }^{1}$
}

\author{
Suprateek Sarker \\ Washington State University \\ U.S.A.

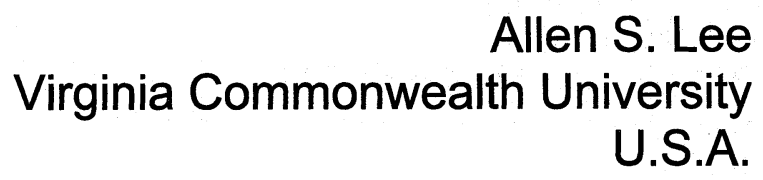

\begin{abstract}
The business process reengineering $(B P R)$ literature maintains that the use of computerized tools for BPR-related tasks such as process modeling, simulation, project management, and human resource analysis has a positive influence on the effectiveness of business process redesigns. Our hermeneutic study of text and text analogues surrounding BPR tool use in two organizations reveals that the use of computerized tools can have two opposing effects on redesign effectiveness. We find that, consistent with the existing BPR literature, $B P R$ tools can indeed enhance redesign effectiveness by providing (1) a structure to the redesign process; (2) cognitive support to the redesigners; and (3) a mode for standardized representation of the redesigns. However, we also discover that the autonomization of electronically represented redesigns and the organizational members'
\end{abstract}

${ }^{1}$ The authors would like to thank John McKinney, Joseph Valacich, Dave Chatterjee, and Sundeep Sahay for their comments on earlier versions of this paper.

The original version of this chapter was revised: The copyright line was incorrect. This has been corrected. The Erratum to this chapter is available at DOI: 10.1007/978-0-387-35566-5_20 
subsequent focus on standardized, detailed, and objectified representations (rather than on socially shared understandings) of the redesign, can lead to an alienation of the original redesigners from the business processes that they envisioned. This alienation, coupled with the redesigners' frustration arising from the frequent and sometimes meaningless changes to the electronically objectified redesigns mandated by other BPR stakeholders in the organization, can contribute to inconsistencies in the redesign, thus resulting in a negative influence of BPR tools on redesign effectiveness.

Our study (1) illustrates the use of the "hermeneutic circle" to understand the role of computerized tools in business process redesign; (2) argues that the role of computerized BPR tools can be better understood by focusing on the sociotechnical interaction of the redesigners with the computerized tools in an organizational context rather than by studying the tools in isolation; and (3) indicates that the effect of tools on redesign effectiveness depends on the relative strengths of the two opposing effects.

Keywords: Business process redesign, BPR tools, interpretive methodology, hermeneutics, sociotechnical perspective.

\section{Introduction}

The academic and trade literature on BPR (business process reengineering) has repeatedly noted that computerized BPR tools have a positive influence on the effectiveness of the product of business process redesign, ${ }^{2}$ as well as the process of redesigning itself (Davenport 1993; Manganelli and Klein 1994; Klein 1998). The BPR literature enumerates a number of alleged advantages of using these tools, but its claims that these tools actually contribute to the effectiveness of redesign have not yet come under empirical scrutiny. An objective of this study is to build on and advance the BPR literature by establishing, based on empirical investigation, how BPR tools actually contribute (or do not contribute) to effectiveness of business process redesign. To achieve this, $\mathrm{we}^{3}$ will (1) use the BPR literature itself to provide a starting point for an understanding of BPR tools in business process redesign ${ }^{4}$ and then (2) pursue an interpretation of not only the nature of influence of computerized BPR tools on redesign

${ }^{2}$ Consistent with the BPR literature, we view business process reengineering as consisting of two analytically separable phases: business process redesign (redesign), and the subsequent implementation of the redesigned processes.

${ }^{3}$ For the sake of readability, we will use the first person plural throughout the paper. Whereas the first author conducted all the fieldwork, the two authors collaborated in developing all the interpretations.

${ }^{4}$ There are other research literatures in the information systems field that can also provide starting points for an empirical study of BPR. Examples are the literatures on information systems implementation and structuration theory. However, because our investigation is making a point of contributing to the BPR literature, it makes more sense to draw our theory from the BPR literature than from other literatures. 
effectiveness, but also the process by which these tools influence redesign effectiveness. Specifically, we will study the use of computerized tools for process mapping/ flowcharting, project scheduling and other project-related documentation as part of the BPR initiatives in two corporations in a large city in the midwestern region of the United States. ${ }^{5}$ We refer to the organizations as MANCO (a manufacturer of environmental products) and TELECO (a telecommunications service provider). Our methodology is hermeneutic, which is an interpretive approach for "reading" text and text-analogues (e.g., Lacity and Janson 1994; Lee 1994; Mueller-Vollmer 1994).

We intend a major contribution of our empirical investigation to be that it refutes the past BPR literature's categorical presumption of a positive influence by BPR tools on the product and process of business process redesign. To accomplish this, we use the BPR literature itself as our starting point for developing an understanding of BPR tool use at two organizations. Next, we show that what we actually observe regarding BPR tool use is at odds with what the BPR literature leads us to expect, whereupon we proceed in an iterative process (using the device of the hermeneutic circle) to identify deficient aspects in the BPR literature and to refine it into an interpretation that is able to account for how BPR tools were indeed used (or not used) in the redesign efforts at the two organizations.

In section 2 of this paper, we briefly review the literature on the role of computerized BPR tools. In section 3, we explain our interpretive methodology, some of the theoretical concepts that we use to interpret the use of computerized BPR tools, and our approach for evaluating redesign effectiveness. In section 4 , we perform the interpretation using the hermeneutic circle and propose an improved way for understanding the role of BPR tools in redesign. Finally, in section 5, we discuss the contributions of this study and avenues for further research.

\section{A Review of the Literature on the Role of BPR Tools}

Articles and advertisements in BPR trade journals indicate that BPR tools will contribute to the effectiveness of the redesign in terms of cost, speed, ease of process-mapping, ease of redesigned process implementation and lowered project risk. ${ }^{6}$ In the research-oriented BPR literature, Kettinger, Teng and Guha (1997) documented their findings from a study of 102 computerized BPR tools, concluding that "the tools survey indicates that an expanding suite of tools are being used to provide structure and information management

\footnotetext{
${ }^{5}$ The first author conducted the field work over a period of approximately 18 months in 1995 and 1996. The research involved both positivist and interpretive stages. To gather data, the first author followed the case study procedures of Yin (1994). After the positivist stage of the research (including hypothesis testing) was completed, the case study's empirical material (including the interview material) then became the "text" for a hermeneutic interpretation. For additional details, see Sarker (1997).
} 
capability ${ }^{7}$ in conducting BPR techniques and possess the potential to accelerate BPR projects" (p. 63).

Consistent with this point of view, Carr and Johannson (1995) explain and illustrate the importance of using such tools, and propose the following "prospective best practice" for BPR initiatives: "Take advantage of modeling and simulation tools" (p. 150). Further highlighting the importance of computerized tools, Davenport (1993, p. 216) points out three "paramount" dangers associated with the failure to pursue opportunities provided by advanced technological tools: first, failures to employ these tools can reduce the pace at which the redesign will progress and this, in turn, can reduce the chance of the initiative's succeeding; second, these tools are likely to improve the quality of the product of redesign; and third, it could indicate that managers are not aware of technological opportunities, consequently undermining the importance of the initiative. Finally, Klein (1998, p. 245) also recognizes the importance of BPR tools, stating:

By using tools, the BPR practitioner expects to improve productivity, finish projects faster, produce higher quality results and eliminate tedious housekeeping work in order to concentrate on value-added work. To produce these benefits, BPR tools should be useable by businesspeople (managers and professionals), not technicians.

An important aspect of useability is "learnability," which Manganelli and Klein (1994) further highlight. They caution that while several benefits (such as "improved productivity," "faster projects," "higher quality levels," and "elimination of tedious work") can be expected from reengineering tools, "these benefits come only after first learning the tool" (p. 214).

To summarize, the BPR literature is unequivocal in its position that computerized $B P R$ tools have a positive influence on redesign effectiveness, especially if the tools are easy to learn and use, where the positive influence follows from the fact that the tools provide (1) a structure for the BPR initiative; (2) cognitive support to the process designers (through the tools' information management capability); (3) a means of documentation (process diagrams, E-R diagrams, Gantt charts, etc.) for enabling communication among different stakeholders of the reengineering initiative; and (4) a means of simulation and playing "what-if" in order to reduce the risks associated with a BPR initiative.

\section{Data Collection, Research Methodology and Theoretical Concepts}

\subsection{Data Collection and Context}

Our empirical material ("data") consists of formal interviews on various aspects of BPR with over 22 BPR stakeholders in the two organizations (MANCO and TELECO) that

\footnotetext{
${ }^{7}$ Kettinger, Teng and Guha view BPR tools with repositories and data indexing features to facilitate "collective knowledge sharing" as having information management capability.
} 
we tape-recorded and transcribed. In addition, our empirical material also consists of informal conversations with stakeholders and observations of organizational members at work in their "natural settings." We provide the case summaries of TELECO and MANCO in this paper's appendix. We examined the empirical material collected from the two organizations through the interpretivist lens of hermeneutics.

\subsection{Methodology}

Hermeneutics originated as an approach for interpreting ancient religious texts that were alien to their contemporary readers, this alienation resulting from the historical and cultural distance between the readers and the authors of the text. Since then, contemporary social scientists have appropriated and suitably modified hermeneutics for the purposes of understanding not only "everyday" written text, but even speech acts and overall human behavior as text analogues (Davis et al. 1992; Ricoeur 1981). In this study, we treat utterances in interviews or informal conversations, and also actions of the BPR stakeholders in the two organizations, as text analogues. These texts were not static but continued to change in meaning with the occurrence of additional events in the organizations over time, and with the evolution in our own interpretation of the events through the use of the "hermeneutic circle."

The hermeneutic circle is a device that allows the reader to comprehend the parts of a "text" in terms of the whole, and the whole in terms of the parts (Davis et al. 1992; Geertz 1983). Perhaps, Thomas Kuhn best illustrates the notion of the hermeneutic circle when he states (see Lee 1991, p. 348):

When reading the works of an important thinker, look first for the apparent absurdities in the text and ask yourself how a sensible person could have written them. When you find an answer...when those passages make sense, then you may find that more central passages, ones you previously thought you understood, have changed their meaning.

There are many schools of thought within the tradition of hermeneutics (MuellerVollmer 1994; Palmer 1979; Smith 1993), where the different schools of thought result from the polarizations of scholarly communities based on ontological and epistemological differences. While we recognize that there are merits to each school, we adopt an approach that is closely related to the school of validation hermeneutics developed primarily by Hirsch (1967) drawing on Dilthey's conception of the hermeneutic circle as a methodological device (Burrell and Morgan 1979; Pressler and Dasilva 1996). Smith (1993, p. 191) has characterized this approach as the most objectivist of the hermeneutic schools in that it assumes that "inquiry is pointless and the concept of knowledge makes no sense in the absence of an independently existing entity to inquire 
about or have knowledge of." ${ }^{\prime 8}$ Smith (pp. 191-192) describes the essence of validation hermeneutics, drawing on Hirsch's work:

An inquirer begins with a hypothesis (or hypotheses) about meaning and then searches for evidence that will call the hypothesis into doubt. If such a falsification evidence is uncovered, the inquirer must revise the interpretation. Throughout the process of constantly testing one's interpretation of meaning, "the direction is still toward increased probability of truth, since the very instability imposed by unfavorable evidence reduces confidence in a previously accepted hypothesis and to that extent reduces the probability of error" (Hirsch, 1967, pp. 151152)....The process of interpretation cannot be reduced to a rulebounded or mechanical process. However, this absence of rules does not mean that "anything goes" because the attempt to interpret an author's meaning is constrained by constant testing, criticism, and so on in the name of the search for truth.

Clarifying the role of validation in hermeneutic interpretation, Hirsch (1967, p. 170) further adds:

The exigencies of validation are not to be confused with the exigencies of understanding....Every interpretation begins and ends in a guess, and no one has ever devised a method for making intelligent guesses. The systematic side of interpretation begins where the process of understanding ends. Understanding achieves a construction of meaning: the job of validation is to evaluate the disparate constructions which understanding has brought forward. Validation is therefore the fundamental task of interpretation as a discipline.

He cautions, however, that any consensus regarding an interpretation achieved through validation is necessarily temporary, and changes as new facts and guesses appear. Consistent with this point-of-view, Davis et al. (1992, p. 304), offer the following guidelines for assessing the "quality of an interpretation":

A "good" interpretation resolves any apparent anomaly or irrationality. A good interpretation, however, need not be (and, in fact, cannot be) final and conclusive because, at least in principle, improvements in the interpretation will always be pursuable.

Thus, in our study, while we recognize that further passes through the hermeneutic circle can result in an improved interpretation, we may discontinue the circular motions around the organizational "text" when we are satisfied by our latest interpretation and are not left confronting any glaring anomalies or "apparent absurdities."

${ }^{8}$ Note that an objectivist ontology does not necessarily entail an objectivist methodology. There can be multiple interpretations of the same independently existing entity in social research, just as there can be competing theories of the same independently existing entity in natural-science research. 


\subsection{Theoretical Concepts Aiding the Interpretation}

While performing the interpretation, in addition to the above guidelines, we also found the hermeneutic concepts of distantiation, autonomization, and appropriation (Boland 1991; Lee 1994; Ricoeur 1981), and the notion of mutual understanding (Churchman and Schainblatt 1965) useful in creating a processual understanding of the use of computerized tools for redesigning business processes. We offer, as background, basic definitions of these concepts, which our subsequent investigation uses. Distantiation, in the context of the redesign efforts at MANCO and TELECO, refers to the separation or the "disconnect" that occurs between a particular "text" (i.e., electronic representation of redesigned processes) and its authors (i.e., the redesigners of the business processes). Autonomization refers to the life that the electronic (textual/graphical) representation of redesign takes on, independently of its original form and even of the intentions of its authors. Appropriation refers to the process by which a party in one socially-constructed world comes to understand the "text" (i.e., redesigns) created in yet another sociallyconstructed world. Mutual understanding involves a dialectical and recursive process (rather than uni-directional processes of communication or persuasion) through which the redesigners and the managers come to understand each other's interpretation of the redesigns. In addition to these concepts, we wholeheartedly adopted the hermeneutic principle that any apparently irrational behavior of people is not a sign that people are irrational, but that they are responding in rational ways to the (likely irrational) circumstances of their context, which would then call for interpretation by us, the researchers (Davis et al. 1994; Lee 1991).

\subsection{Evaluation of Redesign Effectiveness}

Before proceeding with the hermeneutic interpretation, we briefly clarify our approach for evaluating redesign effectiveness in this study. Evaluation of the effectiveness of redesign in BPR is a complex activity, much like the evaluation of information systems implementation success, and no universally accepted criteria exist for such evaluations (Boudreau and Robey, 1996). While several criteria for evaluation of BPR have been discussed in the literature (e.g., Boudreau and Robey 1996; Sethi and King 1998), we believe, drawing on Lyytinen and Hirschheim's notion of "expectation failure" (1987, p. 264), that an assessment of redesign effectiveness requires the recognition of the existence of multiple stakeholders of the redesign initiative, having different values, levels of power and interests, and hence, different expectations; thus, a thorough examination of the evaluations of the various stakeholders of the initiative is necessary. For the purpose of this study, we consider redesign to be effective if different stakeholders state or indicate through actions that such was the case. The fact that we are tying the notion of redesign effectiveness to subjective meaning (i.e., the meanings and perceptions held by the human subjects whom we observe in our study) therefore makes an interpretive research approach appropriate. Furthermore, because we are interpreting manifestations of our human subjects' meanings in the forms of text (their utterances) and text analogues (their actions), hermeneutics is a suitable interpretive approach for this study. 


\section{The Interpretation}

Our interpretation using the hermeneutic circle involved several "circular passes" around the text, with each such iteration ending with a different understanding and also a different puzzle, thus bringing a different set of "data" to our (i.e., the researchers') focus. Each pass through the hermeneutic circle involved four broad steps, which we derive from the work of Davis et al.: first, the identification of breakdowns in our understanding as researchers, resulting from a contradiction between what we already understand (sometimes this is called the "pre-understanding") and what we actually observe; second, the examination of new data relevant to the breakdown being investigated and/or the reexamination (in a new light) of data examined in a previous iteration; third, the surfacing of questionable assumptions (we had made earlier) that contributed to the breakdown in our understanding; and fourth, our revision of the existing interpretation to resolve the breakdown.

\subsection{Passes Through the Hermeneutic Circle}

\section{The first iteration:}

Our objective in the first pass of the hermeneutic circle was to verify our interpretation of the BPR literature regarding computerized tools. Our pre-understanding, based on the BPR literature, was that computerized BPR tools (especially those for flowcharting/ process-mapping and project management) enhance redesign effectiveness by providing (1) a necessary structure to the complex redesign process involving multiple redesigners over an extended period of time; (2) cognitive support to the redesigners who are overwhelmed by the amount of information and the linkages between them; and (3) a standardized/shared notation for representing business processes and other related information.

In the case of MANCO, we learned that the MIS manager had acquired an easy-tolearn user-friendly computer-aided flowcharting tool specifically for use during the information-technology-enabled redesign phase of the reengineering initiative, and that this tool was used at MANCO in the early stages of this phase. However, the use of this tool was discontinued soon after the redesign team ${ }^{9}$ started to meet for the purpose of envisioning how MANCO's information-technology-enabled business processes should work. The redesign team at MANCO accomplished the business process redesign through a process lasting several months in which the team iteratively brainstormed, discussed, and agreed upon different aspects of future business processes and the organization around those processes. Because the redesign team discontinued its use of the flowcharting tools, the evolving redesign primarily existed in the minds of the redesigners in the form of a shared body of knowledge that was not represented as

\footnotetext{
${ }^{9}$ We use the terms "redesign team" and "redesigners" to refer to those organizational members who were formally involved in the rethinking and envisioning of the new business processes and the related organizational aspects. This terminology is consistent with the BPR literature, which breaks down BPR into a redesign stage (in which business processes are redesigned) and a subsequent implementation stage (in which new designs are put into effect).
} 
written or computer-represented text or diagrams. On some occasions, especially for clarification purposes, the redesigners spontaneously hand-drew flowcharts in redesign sessions, ${ }^{10}$ but at no point, was there any attempt to create computer-drawn process diagrams representing the team's then current vision of any business process, even though MANCO had a flowcharting software readily available. Toward the end of the redesign effort, we asked the MIS Manager why the process redesigns had not been represented using the flowcharting package. She said: ${ }^{11,12}$

\section{I had tried to do that...it just worked out to be an exercise for me... basically. If you look in my book that I put together before the project started, I had... two chapters... "business as it is" and "business as it will be," and the "will be" is still blank. The vision that we have right now is kind of a high level and it hasn't really come to fruition yet...we will write (draw) it after we do it.}

She was convinced that the use of computerized flowcharting tools would not contribute to a more effective redesign, especially in light of the iterative approach to process redesign that the reengineering team had adopted. According to the MIS manager, an important advantage of not using the flowcharting tool was that the design could then remain very flexible and could also be continuously challenged and modified by the team members, who continually encountered different concerns as they learned more about the processes being redesigned and about the process-enabling software options. When asked if she would have used BPR tools in a larger company, the MIS manager indicated that she probably would have to, although (interestingly) not because such tools would inherently enhance the effectiveness of the process redesigns, but because they could help generate the "professional documents" and contribute to the legitimacy of the redesigners in larger organizations:

In a larger company you have to justify things a lot more....And you have to get sign-offs and go through the levels of approval and all this stuff...but here, it's not like that.

All MANCO redesigners whom we interviewed expressed the view that the use of computerized tools would not have enhanced redesign effectiveness. Our own observation during the redesign sessions also supported the team-members' shared view that the absence of computerized graphical tools helped the team to operate flexibly without getting bogged down on details and diagraming conventions.

\footnotetext{
${ }^{10}$ Even the hand-drawn flowcharts were not saved for future use; they were drawn for the purpose of explanation and clarification only.

${ }^{11}$ When quoting organizational members, we place the text in italicized font. Furthermore, because the same text can come to have different meanings in different passes through the hermeneutical circle (please also refer to the quotation of Kuhn, above), we will additionally place some portions of the text in bolded font to help emphasize the particular meaning we are forming at the current stage in our interpretation.
}

${ }^{12}$ Space limitations preclude us from presenting a full complement of the organizational members' remarks and other empirical material. It is available in Sarker (1997). 
The TELECO reengineering team members, on the other hand, reported extensive use of software for flowcharting/process-mapping and also for project management (although not for simulation). In general, the TELECO redesigners had a positive disposition toward such tools and appeared to believe that the tools had indeed contributed to a better redesign of the business processes. A TELECO redesigner said:

[W]e used Microsoft Project, a flowcharting software... Visio flowcharting software, WordPerfect documents... and PowerPoint....I would say Visio and Project helped us the most during the redesign phase. We used Visio to create all the process flowcharts....it was just fantastic...and Project...we really stretched its capabilities and used it to integrate plans across all the people involved...I would say that the design would not have been as effective without the use of the tools.

Based on the interviews with the redesigners, we concluded that computerized BPR tools had had a positive influence on the effectiveness of the business process redesign at TELECO.

In summary, while we found TELECO's experience to be consistent with the literature on BPR tools, MANCO's experience contradicted our understanding of this literature. In particular, at MANCO, we observed that (1) the MIS manager discontinued the use of a user-friendly and easy-to-learn flowcharting tool that had been acquired specifically to facilitate the redesign and (2) the redesign team members stated that the tools would not have made the redesign more effective (and, in fact, could have contributed negatively to effectiveness by reducing flexibility). The only interpretation that we could offer at this point was that MANCO's use of BPR tools was different in some unique way due to which the organization had experienced a negative effect of the tools. However, even we ourselves were not quite satisfied with this particular interpretation.

\section{The second iteration:}

In an effort to resolve the apparent breakdown, we returned to the organizations, asking the redesigners questions that we hoped would prod self-reflection among them. We hoped that some additional organizational "text" would reveal itself and help us make sense of the breakdown in our understanding. Finally, a redesigner at TELECO provided a way for us to resolve the breakdown. In the course of an interview, he burst out unexpectedly:

The problem is, if you have a tool, you become a slave to that tool.... we did more damn presentations, to try and get a buy into what we were doing, that we spent too much time....The business of producing and documenting was very cumbersome... we refined the hell out of this thing... and tool-smithed it so many times, it was ridiculous! 
This outburst of the TELECO redesign team member immediately led us to question our starting assumptions. We had assumed that process losses during redesign initiatives (those that are not supported by computerized tools) occur primarily due to cognitive limitations of team members, due to confusion in the process of redesign, or due to the lack of a standard notation for representing existing and envisioned business processes. However, in the case of TELECO, while the tools appeared to have contributed in all three areas mentioned above, we were no longer convinced (given the outburst of the redesigner) that the tools had positively contributed to the redesign. Consequently, our conclusion at the end of this iteration was that BPR tools have a negative effect on redesign effectiveness $!^{13}$

\section{The third iteration:}

Yet, the interpretation that computerized BPR tools have a negative effect on the redesign seemed extremely counter-intuitive. In light of so much "evidence" in the trade and academic journals regarding the positive experiences of BPR tool users, this new interpretation did not seem to ring true to us, presenting us with an anomaly that had to be explored further. We recalled that one of MANCO's redesigners, who had provided us with many insights through his critical thinking, had mentioned his uneasiness with the lack of structure in the design process: ${ }^{14}$

\section{It [the flowcharting tool] would have provided us with some guid- ance.}

This made us question yet another assumption that we had unwittingly used in this interpretation: computerized graphical tools affect redesigns in only one direction. Was it not conceivable that BPR tools can have both a positive influence and a negative influence on redesign effectiveness?

\section{Fourth iteration:}

At the starting point of the fourth iteration, we found ourselves confronting two breakdowns in our understanding regarding the use of BPR tools at MANCO and TELECO. The first breakdown was related to our understanding that the BPR tools do have (in certain circumstances) a positive influence on redesign effectiveness by providing structure, standard notation and cognitive support. Because structure, standard notation and cognitive support become more relevant with increasing size, it seemed sensible for us to assume that a larger reengineering team within a larger organization would experience the benefits from using the tools. Yet, as the redesign team member's outburst revealed, there was a significant level of dissatisfaction (and by implication,

${ }^{13}$ After all, MANCO also appeared to have experienced a somewhat negative influence of BPR tools.

\footnotetext{
${ }^{14}$ This particular redesigner too had said that overall the use of flowcharting tools would not have made the redesign at MANCO more effective.
} 
negative influence on redesign effectiveness) in TELECO (which was the larger of the two organizations with a considerably larger reengineering team) regarding the use of computerized tools.

The second breakdown that we were experiencing was that we did not understand why MANCO had discontinued the use of the BPR tools that it had acquired even though a respected member of the redesign team had expressed the need for a computerbased redesign support tool.

In attempting to resolve these breakdowns, we re-examined what a TELECO reengineering team-member had said when reflecting on his experience with the tools: ${ }^{15}$

\begin{abstract}
The problem is, if you have a tool, you become a slave to that tool.... we did more damn presentations to try and get a buy into what we were doing, that we spent too much time...I mean producing those things. The business of producing and documenting was very cumbersome...we refined the hell out of this thing... and toolsmithed it so many times, it was ridiculous....they're only as good as how people follow them, because if there is no real dedication to plans... all the tools in the world won't.
\end{abstract}

This expression of frustration indicated to us that the computerized tools for representing redesigns could cause an alienation (or distantiation, in the hermeneutic sense) of the designs from its original formulators. We could also see that much of the unhappiness experienced by the redesign team member was due to the fact that he had been forced to make "meaningless" changes.

In attempting to resolve our second breakdown, two quotations that we had previously examined came alive in a different way, triggering an interpretation that could resolve the contradiction:

MANCO redesigner: It would have provided us with some guidance...initially.

MANCO MIS manager: In a larger company, you have to justify things a lot more.... and you have to get sign-offs and go through the levels of approval and all this stuff.

On examining these "data," we were even more convinced that BPR tools do not influence redesign effectiveness in one direction only. Also, we realized that, in addition to providing a structure, some cognitive support, and a mode for standardized representation, computer-based BPR tools serve another important social function in the context of BPR: that of helping to justify a redesign through the layers of bureaucracy by creating a formal or "professional" appearance of the redesign.

\footnotetext{
${ }^{15}$ Our return to a text, which we have already examined, is deliberate. In hermeneutic interpretation, "[w]hen you find an answer...then you may find that more central passages, ones you previously thought you understood, have changed their meaning" (Kuhn, quoted above). Such a return does not "privilege". a given text (or the person who authored it), but assures that it receives due consideration in fitting into a coherent, overall interpretation. This stands in contrast to an approach based on random sampling, in which each datum would "count" equally and only once.
} 
The revised understanding emerging toward the end of the fourth pass was that the BPR tools can actually be helpful in the early stages of the redesign process in providing a structure and buffer against the redesigners' cognitive limitation of comprehending and retaining unfamiliar process related designs immediately. The tools could also help in creating "professional-looking" redesigns that could be presented to management for approval. In the later stages, this very structure and the ability to create professionallooking redesigns could act as a constraint to creative thinking, and could instead encourage a bureaucratic mind-set with an obsession on maintaining consistency in the diagrams and other unimportant details. Our new interpretation of the situation better accounted for the dissatisfaction of the TELECO redesigner as well as MANCO's decision to discontinue the use of computer-based BPR tools.

\title{
The fifth iteration:
}

Our interpretation, up to this point, seemed to suggest that BPR tools should be used only in the early stages of the redesign or to satisfy bureaucratic requirements; yet, many organizations (including ones that cannot be characterized as "bureaucratic") have been reported to use the tools effectively throughout the life cycle of the initiatives. To address this issue, we revisited some "data" that we had used for surfacing an interpretation for a previous iteration.

The MANCO MIS manager: In a larger company, you have to justify things a lot more.... and you have to get sign-offs and go through the levels of approval and all this stuff...but here, it is not like that... at least not now... it used to be.

\begin{abstract}
A TELECO redesign team member: The problem is, if you have a tool, you become a slave to that tool....we did more damn presentations to try and get a buy into what we were doing, that we spent too much time....The business of producing and documenting was very cumbersome...we refined the hell out of this thing... and toolsmithed it so many times, it was ridiculous....they're only as good as how people follow them, because if there is no real dedication to plans... all the tools in the world won't help.
\end{abstract}

We noticed that specific words in the text newly stood out as we searched for a way to resolve the anomaly confronting us. For example, we found the MIS manager's words "In a large company, you have to justify things lot more...but here, it is not like that... at least for now...it used to be" and the TELECO redesigner's words "you become a slave to that tool.....we refined the hell out of this thing...it was ridiculous....If there is no dedication to plans...all the tools in the world won't help" to be prominent in our view. The interpretation that we now crafted was that decisions to use BPR tools, and the effects of BPR tools, are dependent on the context of their use. Tools can provide much needed structure and cognitive support throughout the life of the project; however, care must be taken so that an alienation of the authors from the design does not occur. Too much emphasis on the tools may result in the redesign (represented in electronic form) 
being taken-for-granted as an "objective" product that is distantiated from the redesigners and autonomized. The autonomized design could then subsequently end up in the hands of different stakeholders, in different socially constructed worlds, who initiate corrections and modifications even when they have no awareness of the original context of the redesign. We also came to appreciate that a standardized representation of the redesign does not guarantee a uniform interpretation/appropriation across different stakeholder groups (owing to the different socially constructed worlds to which different groups belong, and the different frames that they use to interpret a given representation [Orlikowski and Gash 1994]), and also that a shared social context and mutual understanding among different designers and management is key to a positive influence of computerized BPR tools on redesign effectiveness.

Another point worthy of emphasis was that we were beginning to see the redesigners' interaction with the tools in a particular context (and not the tools themselves) as influencing the redesign in a positive or a negative manner. Interestingly, this indicated a shift in the underlying theoretical orientation of the understanding that was evolving through the interpretation, from a technological-imperative orientation to a sociotechnical orientation (Markus and Robey 1988).

At this point, it appeared to us that we had a satisfactory understanding; we had validated it to the extent our text allowed us and there were no longer any anomalies or breakdowns confronting us. Thus, we decided not to undertake further interpretive iterations. The processes of redesign at TELECO and MANCO, as framed in our hermeneutic interpretation, are summarized in Figure 1.

\subsection{Putting the Pieces Together: A Recapitulation of Insights Gained Through Interpretation}

Our interpretation revealed that computerized BPR tools do provide a structure to organize redesign activity and a common language to aid redesign team members in communicating and sharing their emerging visions, both among themselves and with other stakeholders such as the members of top management. The tools provide a buffer for team members against their cognitive limitations of comprehending information about unfamiliar business processes (whether existing or envisioned). However, once the team members become sufficiently familiar with the existing processes and visions, the "structure" of the existing designs, whether in an electronic medium or on paper, can act as a constraint to creative thinking about the processes. As a result of this "structure," redesign team members no longer engage in creative thinking in an ad hoc fashion, but instead tend to adopt a bureaucratic mind-set that leads them to focus their attention on maintaining consistency in the diagrams and arguing about unimportant details. Also, the process diagrams, once formalized on paper or in electronic media, become distantiated from their authors and thereafter become autonomized. Consequently, different redesign team members, owing to different perspectives associated with their different social contexts, can come to understand the same redesign differently, and can accordingly make changes to these formalized redesigns/diagrams, leading to an alienation of the redesigns from their original authors. This loss of control and personal ownership, in turn, can lead to the original authors losing interest and commitment to the redesign.

Also, when this redesign is presented to top management, who typically exist in a socially constructed world different from that of the redesign team members, they (the 
PROCESS AT TELECO

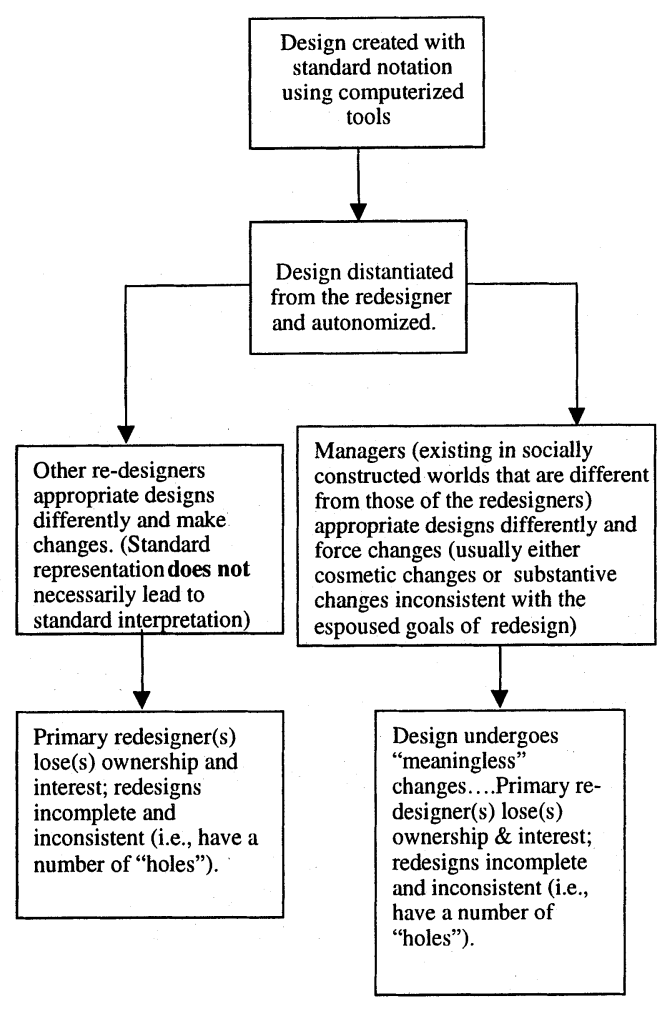

PROCESS AT MANCO

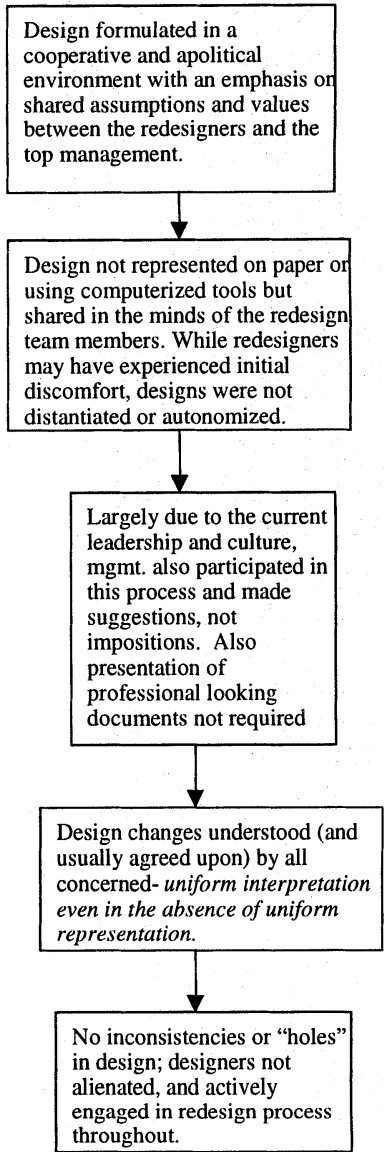

Figure 1. The Processes of Redesign

members of top management) can then appropriate the redesign within their own context, thus obtaining yet another different understanding of the redesign as compared to the understanding of the redesign authors. This is evident in TELECO where the redesigners were keen to show how cross-functional coordination would be enabled by their envisioned process while management was instead interested to see how many head-counts had been reduced, or how many process owner positions (for themselves) had resulted from the redesign effort. Having more power than the redesigners in determining the final product of redesign, management imposed changes and refinements that were, often times, not important to the business process redesign and, thus, meaningless to the redesigners; yet, the redesign team members had no choice but to comply helplessly with those directives resulting in the kind of bottled-up frustration captured in their own usage of words such as "slave," "damn presentations," "refined the hell out of," "ridiculous," and "all the tools in the world won't help." It is clear that making changes to the redesign had become a detached task for the TELECO 
redesigner - a task that the redesigner then had to accomplish in order to satisfy someone else's wishes, as opposed to making changes for "improving our design." Such distantiation of the redesign document from its authors (the redesigners), and the alienation experienced during the process of redesign, both serve to account for our observations of glaring shortcomings in the redesign called "holes" (incompleteness and inconsistency in process redesigns) that became apparent during the later implementation of the redesigned processes at TELECO.

In contrast, while MANCO redesigners may have experienced some initial difficulty in comprehending the organizational business processes and getting accustomed to the redesign project, subsequently their personal involvement and their relatively apolitical environment guaranteed that the redesign was a part of their respective and also shared stocks of knowledge. By not having the redesign on paper or in electronic media, MANCO stood the risk of not having any standardized representation at all, although having a standardized representation does not, by any means, guarantee a standardized interpretation. In fact, the taken-for-granted objectivity of electronically represented process maps could lead to less effort in developing a shared understanding of the redesign among team members, thereby causing serious confusion in the team's redesign efforts.

MANCO's organizational context, instead, encouraged a standardized interpretation of a mentally-shared conceptual representation of the processes among the redesign team-members. In addition, because the senior VP and other managers were closely participating in the project, they too were part of the same socially constructed world of the redesigners, and thus shared the same interpretation of the emerging redesigns. Whenever redesign changes had to be conveyed to the management, it was done personally, through a process of mutual understanding (i.e., the interpretation with immediate clarifications from both sides) rather than through the process of "halfduplex" communication that occurred in TELECO, involving a uni-directional presentation from the redesign team members followed by uni-directional change directives from the management.

The graphical representation (Figure 2) shows the two opposing impacts of the computerized tool use on redesign effectiveness: a positive impact arising from the structure, the cognitive support, and the standards for process representation provided by the tools; and a negative impact arising from narrow interpretations (by organizational members) of standardized representations of processes, the depersonalization of the reengineering vision, and the alienation of the vision from the redesigners. We emphasize that, in Figure 2, we do not intend the curves to serve as precise depictions of the forces that influence redesign positively and negatively. Rather, we intend them to show that the direction of the overall effect of BPR tools on the redesign effectiveness (depicted by curve $\mathrm{C}$ ) depends on the relative strengths of the two opposing forces (depicted by curves A and B respectively).

\section{Conclusion}

We believe that our study makes two important contributions. First, methodologically, it illustrates how the hermeneutic circle can aid in the development of a "good" interpretive understanding (Davis et al. 1992) of an IT-related social phenomenon. Second, through a hermeneutic interpretation of organizational text surrounding 


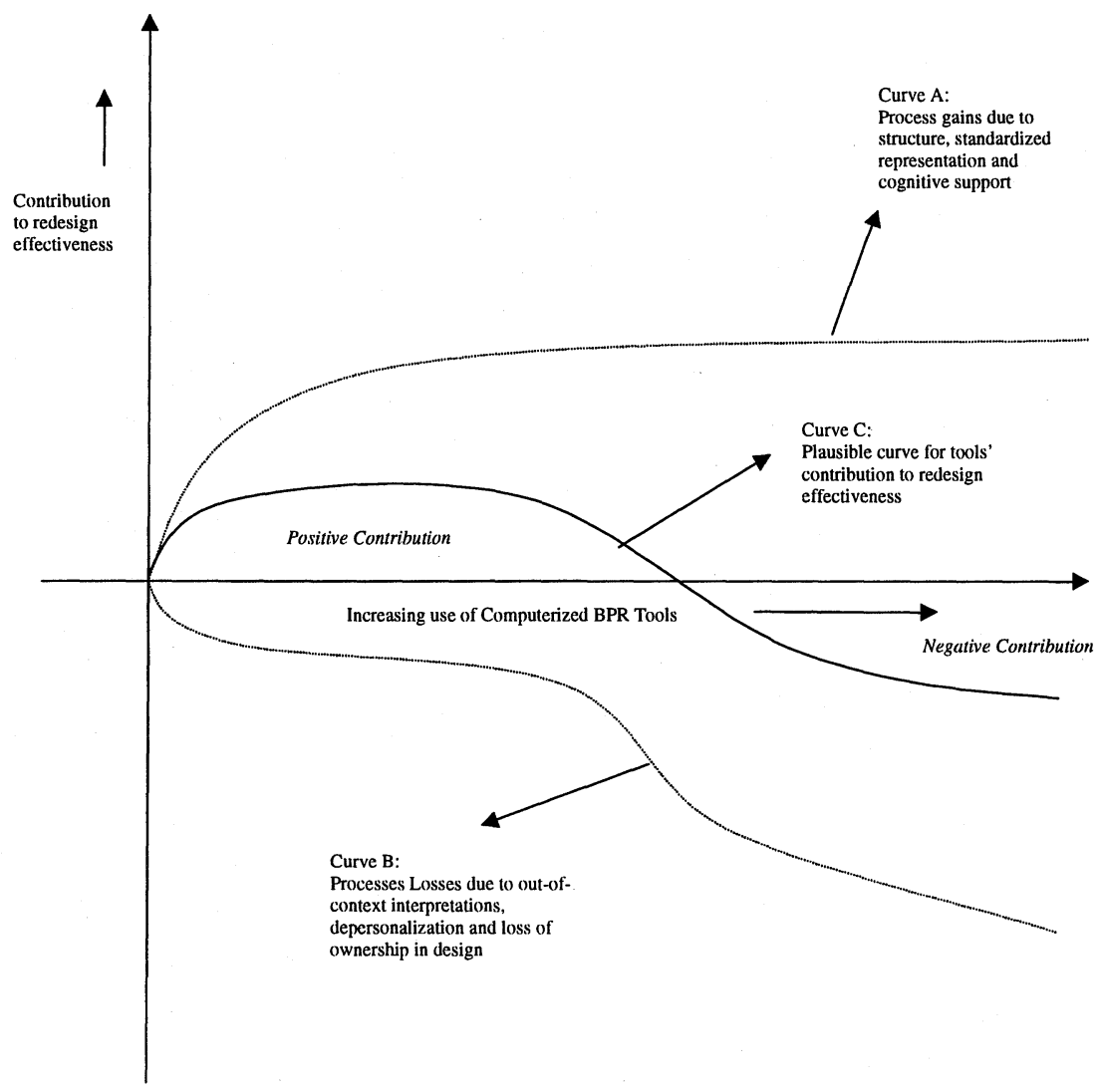
Figure 2. A Preliminary Understanding of BPR Tool Use
Developed from the Interpretive Study

computerized BPR tool use (or lack of use) in two organizations, we have learned that BPR tools need to be studied from a sociotechnical perspective, and that the overall direction of influence of a BPR tool on redesign effectiveness depends on whether or not the context and degree of the tool's use result in the positive impacts (depicted in Curve A, Figure 2) dominating the negative impacts (depicted in Curve B, Figure 2), or vice versa. We have also come to an understanding of the process by which the negative impact of computerized BPR tools could have occurred or could have been avoided (Figure 1).

While our hermeneutic study provides an alternative understanding of how BPR tools influence redesign effectiveness, more research needs to be done in this area. We see future research on this topic taking two inter-related forms (Lee 1991): for researchers seeking an even deeper understanding of the processes that enable and constrain redesign, a fruitful way to pursue research would be to conduct further interpretive examinations of BPR tools in organizational contexts using ethnographic or hermeneutic approaches; for researchers seeking findings that fit the positivist variants of the concepts of generalizability and generality, we recommend the use of deductive 
positivist studies that attempt to "operationalize" insights gained from the intensive interpretive examination of BPR tools, as in this study. These suggestions pertain to theory refinement and development, which would address the problem of the paucity of theory in the existing BPR literature. Efforts to build theory in BPR can, of course, also benefit from targeting other established areas of information systems research. For instance, now that our interpretation has established the significance that can characterize the interactive nature of the relationship between computerized BPR tools and their social context, it would appear appropriate and fruitful for future research on the effectiveness of BPR tool use to avail itself of insights from the literatures of sociotechnical systems theory and adaptive structuration theory.

The desirability of refining our hermeneutic interpretation with research literatures in addition to that of BPR, the necessity of continuing the process of interpretation (whether with observations at the same firms, MANCO and TELECO, or at additional sites), and the option of even beginning the interpretation process anew (for instance, embarking with a pre-understanding not from the BPR literature, but from the IS implementation literature) all serve to highlight the fact that alternative, and competing, interpretations are always possible and even welcome. Improvements in a hermeneutic interpretation are always possible, but the reader (the interpreter) may rest once he or she is satisfied that the latest reading (interpretation) has resolved the remaining anomalies or "apparent absurdities" (Kuhn, quote above) in the text or text analogue.

\section{References}

Burrell, G., and Morgan G. Sociological Paradigms and Organizational Analysis. London: Hienemann, 1979.

Boland, R. J. "Information System Use As A Hermeneutic Process," in Information Systems Research: Contemporary Approaches and Emergent Traditions, H. E. Nissen, H. K. Klein, and R. Hirschheim (eds.). Amsterdam: Elsevier-North Holland, 1991, pp. 439-457.

Boudreau, M., and Robey, D. "Coping with Contradictions in Business Process Re-engineering," Information Technology and People (9:4), 1996, pp. 40-57.

Carr, D. K., and Johansson, H. J. Best Practices in Reengineering: What Works and What Doesn't in the Reengineering Process. New York: McGraw-Hill, 1995.

Churchman, C. W., and Schainblatt, A. H. "The Researcher and The Manager: A Dialectic Of Implementation," Management Science (11:4), February, 1965.

Davenport, T. H. Process Innovation: Reengineering Work Through Information Technology. Boston: Harvard Business School Press, 1993.

Davis, G. B.; Lee, A. S.; Nickles, K. R.; Chatterjee, S.; Hartung, R.; and Wu, Y. "Diagnosis of an Information System Failure: A Framework and Interpretive Process," Information and Management (23:5), 1992, pp.293-318.

Geertz, C. "From the Native's Point of View: On the Nature of Anthropological Understanding," in Local Knowledge, C. Geertz (ed.). New York: Basic Books, 1983, pp. 55-70.

Hirsch, E. D. Validity in Interpretation. New Haven, CT: Yale University Press, 1967.

Lacity, M. C., and Janson, M. A. "Understanding Qualitative Data: A Framework of Text Analysis Methods," Journal of MIS, Fall 1994, pp. 137-155.

Lee, A. S. "Electronic Mail as a Medium for Rich Communication: An Empirical Investigation Using Hermeneutic Interpretation," MIS Quarterly (18), June 1994, pp. 143-157.

Lee, A. S. "Integrating Positivist and Interpretivist Approaches to Organizational Research," Organization Science (2:4), 1991, pp. 342-365.

Kettinger, W. J.; Teng, J. T. C.; and Guha, S. "Business Process Change: A Study of Methodologies, Techniques and Tools,” MIS Quarterly, March 1997, pp. 55-80. 
Klein, M. M. "Reengineering Methodologies and Tools: A Prescription for Enhancing Success," in Organizational Transformation through Business Process Reengineering, V. Sethi and W. R. King (eds.). Upper Saddle River, NJ: Prentice Hall, 1998, pp. 243-251.

Lyytinen, K., and Hirschheim, R. "Information Systems Failures: A Survey and Classification of the Empirical Literature," Oxford Surveys in IT (4), 1987, pp. 257-309.

Manganelli, R. L., and Klein, M. M. The Reengineering Handbook: A Step-By-Step Guide to Business Transformation. New York: AMACOM, 1994.

Markus, M. L., and Robey, D. "Information Technology and Organizational Change: Causal Structure in Theory and Research," Management Science (34:5), May 1988, pp. 583-598.

Mueller-Vollmer, K. The Hermeneutics Reader. New York: Continuum, 1994.

Orlikowski, W. J., and Gash, D. "Technological Frames: Making Sense of Information Technology in Organizations," ACM Transactions on Information Systems (12:2), April 1994, pp. 174-207.

Palmer, R. E. Hermeneutics: Interpretation Theory in Schleiermacher, Dilthey, Heidegger, and Gadamer. Evanston, IL: Northwestern University Press, 1979.

Pressler, C. A., and Dasilva, F. B. Sociology and Interpretation. New York: State University of New York Press, 1996.

Ricoeur, P. Hermeneutics and the Human Sciences, J. B. Thompson (ed.). New York: Cambridge University Press, 1981.

Sarker, S. The Role of Information Technology and Social Enablers in Business Process Reengineering: An Empirical Investigation Integrating Positivist and Interpretivist Approaches, Unpublished Doctoral Dissertation, Department of Accounting and Information Systems, University of Cincinnati, 1997.

Sethi, V., and King, W. R. (eds.). Organizational Transformation Through Business Process Reengineering. Upper Saddle River, NJ: Prentice Hall, 1998.

Smith, J. K. "Hermeneutics and Qualitative Inquiry," in Theory and Concepts in Qualitative Research: Perspectives from the Field, D. J. Flinders and G. E. Mills (eds.). New York: Teachers College Press, 1993.

Yin, R. K. Case Study Research: Design and Methods. Beverley Hills, CA: Sage, 1994.

\section{About the Authors}

Suprateek Sarker is an Assistant Professor of Information Systems at the Washington State University. He received his Bachelor of Computer Science and Engineering from Jadavpur University (India), MBA from Baylor University, M.S. in CIS from Arizona State University, and Ph.D. in Information Systems from the University of Cincinnati. Currently, he teaches undergraduate and graduate courses in systems analysis and design and database systems. His research interests include IT-enabled organizational change, virtual teamwork, electronic commerce, IS failures, and qualitative research methodologies. Suprateek can be reached by e-mail at sarkers@cbe.wsu.edu.

Allen S. Lee is a professor in the Department of Information Systems at Virginia Commonwealth University and the Eminent Scholar of the Information Systems Research Institute. He has been a proponent of qualitative, interpretive, and case research in the study of information technology in organizations. He is Editor-in-Chief of MIS Quarterly and co-editor of the book, Information Systems and Qualitative Research (London: Chapman \& Hall, 1997). Allen can be reached by e-mail at AllenSLee@csi.com. 


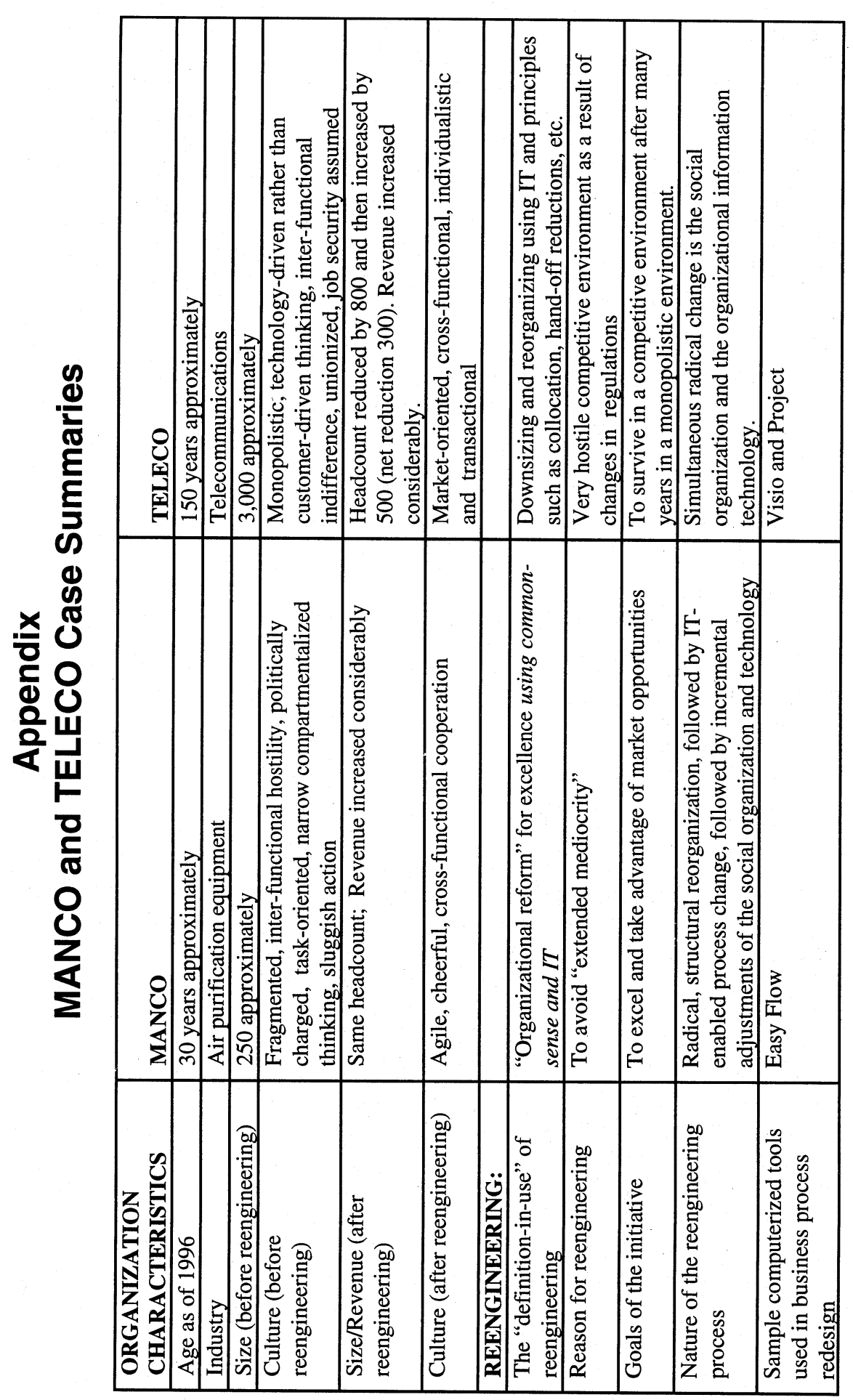




\begin{tabular}{|c|c|c|c|c|c|c|c|}
\hline & 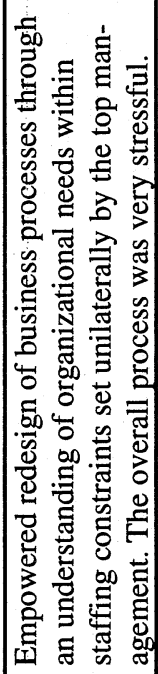 & 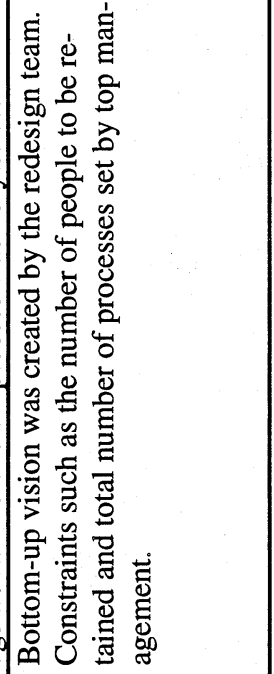 & 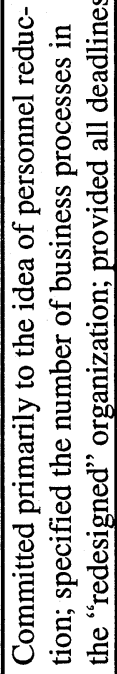 & 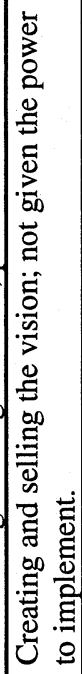 & 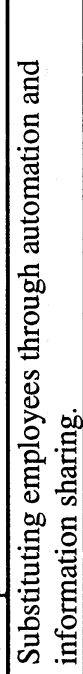 & 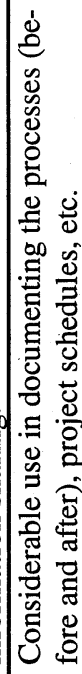 & 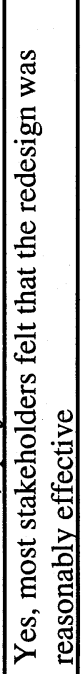 \\
\hline & 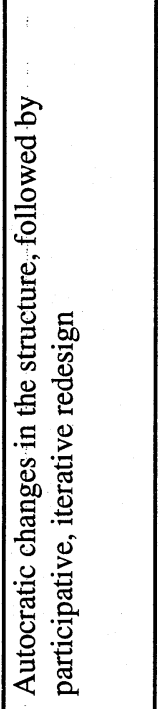 & 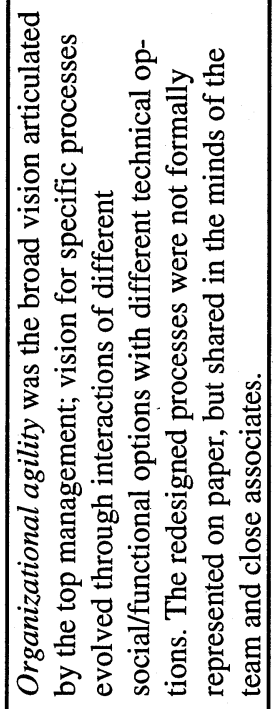 & 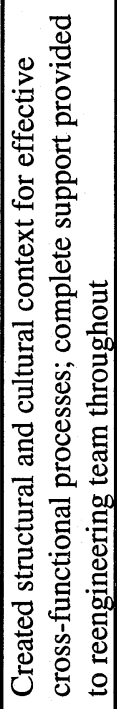 & 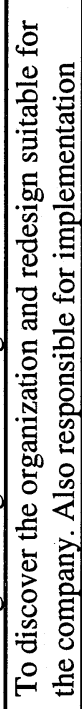 & 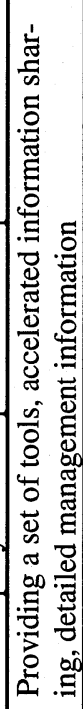 & 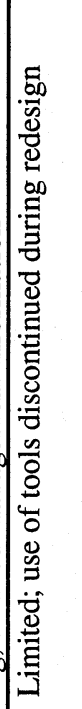 & 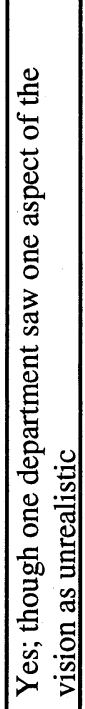 \\
\hline & 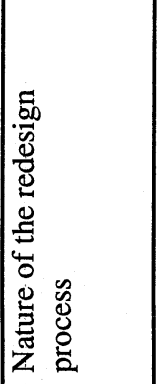 & 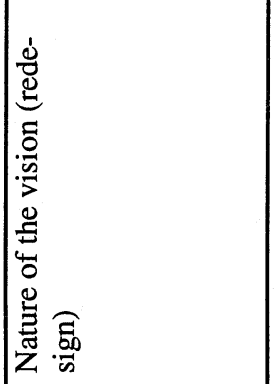 & 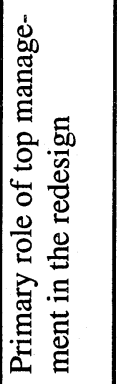 & 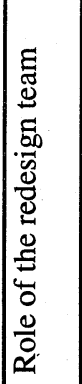 & 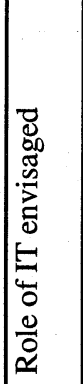 & 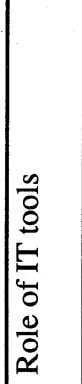 & 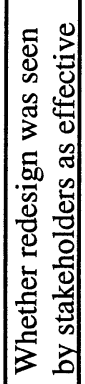 \\
\hline
\end{tabular}




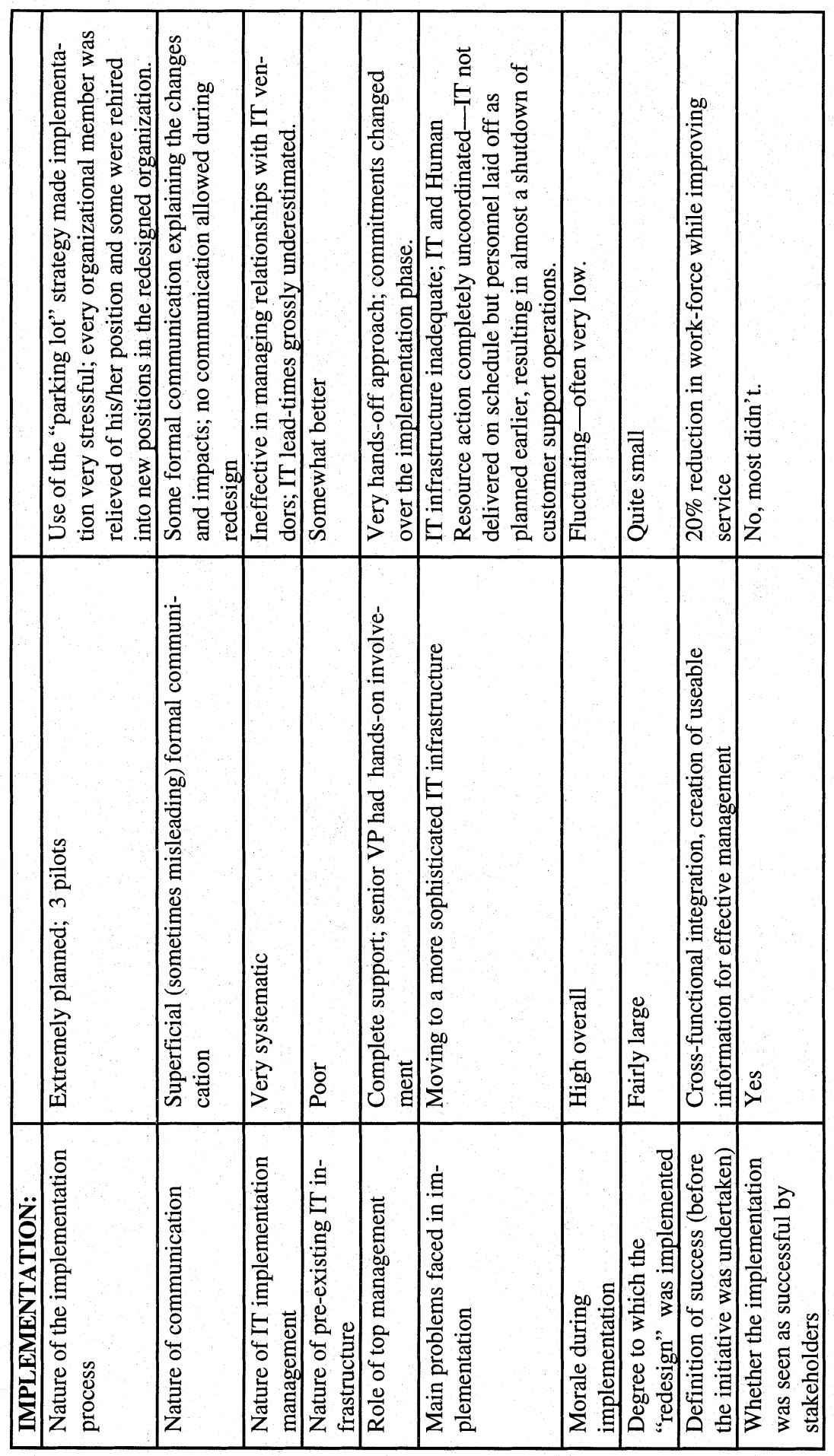

